\title{
R-D-L me this: A simple semi-directed learning approach to teaching first year physics students.
}

\author{
Mears, M. ${ }^{1}$ \\ ${ }^{1}$ The University of Sheffield, UK
}

\begin{abstract}
Students often enter physics courses at higher education with a background experience of "spoon fed" learning yet academic staff expect students to engage in self-directed learning. The Revise, Do, Learn method presented here provides a first intermediary step between "spoon fed" and independent learning. A small to moderate positive effect $(d=0.38)$ was found between subsequent cohorts that, when considered with the minimal time and effort required to implement the method, provides an easy win for improving student learning.
\end{abstract}

\section{Introduction}

"For a thousand years, [the University] has not only served as a custodian and conveyor of knowledge, wisdom, and values..."

Duderstadt, 2000, p6, italics added

The University has long been considered both a creator and repository of knowledge, though the perception of what knowledge is and how it is transferred has shifted over time. In 1852 John $\mathrm{H}$. Newman described the University as "...a place of teaching universal knowledge..." (Newman, 1996, p3) in a manner much akin to a worldly trader delivering well-defined goods to the wanting masses. More recently Joseph Raelin describes this style of education as "...seeing knowledge as tangible and permanent, [requiring] it to be transferred from the mind of the knower into the mind of the current or future user." (Raelin, 2009, p402, italics added).

This one-directional, almost transactional ideological model of higher education has changed to reflect more upon students being "...transformed and shaped..." (Duderstadt, 2000, p10) and that students must be active learners rather than passive recipients of knowledge. Observations that the traditional didactic method of teaching does not produce the desired results nor engage students as learners (Jaffe, 1998) has led to innovations in teaching methods including discussion teaching (Christensen, 1991), technology enhanced learning (Seery and McDonnell, 2013), flipped teaching (Lancaster, 2013; Kensington-Miller et al, 2016) and problem based learning (Overton and Randles, 2015). Such a model is most certainly an admirable ideology to which all higher education institutions should aspire; however the changes needed to implement this methodology are hindered by factors including organisational pressure to conform to institutional norms (Meyer and Rowan, 1977) alongside habit, history, logistics and traditions within departments and institutions (Berger and Luckmann, 1967; Hinings and Greenwood, 1988) as well as societal, political and economic agendas (Dehler and Welsh, 2014).

Even when there is resistance to changing the way in which students are taught it does not come solely from the higher education organisations. Educators may over-structure the curriculum to allay student anxiety that Raelin (2008) notes can occur when students are confronted "....with their own state of not knowing and ... the fears that such not knowing can produce." Students and teachers alike are under multiple pressures to succeed, the former often taking on significant debts to study whereas the latter need to teach larger cohorts of 'customers' in a mass market economy of education (Trow, 1974; Gibbs, 2010). Smith (2008) makes the point that "...spoon-feeding is a short-cut to students' academic success, cutting out the time-consuming activity of 
working out what they need to learn." Surface learning has become the prevailing strategy for coping with increased workloads, pressures and expectations despite being widely criticised for its failure to result in students that can think beyond what they have been instructed and have learnt by rote (Cole, 1990).

This work explores a technique introduced to first year undergraduate students in the Department of Physics and Astronomy at the University of Sheffield, UK. The rationale behind the technique comes in part from my experience that the transition of students from dependent to independent learners is something that must be gradual throughout their studies. Students typically leave secondary education with an experience of memorising the notes provided, often with their expectation that this model of teaching and learning will continue, and so we must slowly but incrementally guide students away from this spoon-feeding mentality.

\section{Method and Implementation}

\section{Revise, Do, Learn - The R-D-L method}

The authors observation that new students have an expectation of being spoon-fed prompted the development of a halfway measure that would provide students with the familiar comfort of regular instructions and signposting but introduces them to the practice of selecting and directing their own learning. The developed method, the "Revise, Do, Learn" or R-D-L method involves a single slide at the end of a didactic lecture that includes the three components, an example of which can be seen in figure 1.

Students were told in the first lecture about the R-D-L approach with the following definitions:

- "Revise" gives the pages of the course textbook (Young and Freedman, 2012) for the material covered in and around the lecture topic

- "Do" are all of the textbook questions related to the lecture topic and covered in the "Revise" section above

- "Learn" gives a smaller section of the textbook that provides a general overview of the topic for the next lecture.

\section{R-D-L}

Revise: Sections 1.1 (page 1) - 2.4 (page 52) [ignore vectors for now]

Do: $\quad$ Q2.1-Q2.34

Learn: Sections 2.5 and 2.6 (pages 52- 57) Q2.35 - Q2.54

Figure 1 Screenshot of R-D-L slide from first mechanics lecture. Note the wide range of pages and questions in the Revise and Do sections that cover all possible pages and questions related to the topic in the course textbook.

Students were told that the R-D-L material was only for their own use in supporting their learning and preparation for examinations, and that the questions in the "Do" sections did not need to be submitted as part of their course work. The pre-lecture reading given in the "Learn" section was still covered in the lecture (as opposed to many flipped lecture formats that emphasise independent learning in preparation of in-class discussions (Lancaster, 2013) and students were informed that the prereading was for them to get "a head start" if they wanted.

Engagement with the R-D-L material was not monitored as part of the course and the method was not used in any other course within their studies.

\section{Implementation at the University of Sheffield}

All students undertaking any physics-based degree at the University of Sheffield must take the compulsory "Mechanics, Waves, Optics and Special Relativity" module in their first semester of the first academic year. This module, known in shorthand by the module code PHY101, is split into the four topics given in the module title and a different member of staff teaches each topic. Each 12-lecture topic was delivered in six-week sections, with two topics running simultaneously (i.e. Mechanics and Optics lectures had two lectures each in 
the first 6 weeks, then Waves and Special Relativity for the same). Note that in the remainder of this work the Optics section is not considered as there was a change in the member of staff teaching between the academic years 2013-2014 and 2014-2015.

The R-D-L method was introduced by the author into the Mechanics section of PHY101 in the 2014-2015 academic year. Content and order of lectures remained identical between 2013-2014 and 2014-2015 for all three sections, excluding the introduction of the R-DL. Examinations for the two academic years under study followed the same format in terms of timing, duration, weighting and design. The examinations were standardised for difficulty by way of peer review by colleagues who have experience in setting examinations. The Waves and Special Relativity sections were combined and used as an indicator for intrinsic ability between the two cohorts due to their total consistency between years.

\section{Learning outcome: Examination scores}

The average examination scores for Mechanics were $63 \%$ and $71 \%$ for $2013-2014$ and 2014-2015 respectively, and the averages for the combined Waves and Special Relativity sections were 55\% for 2013-2014 and 59\% for 2014-2015. There was a statistically significant difference between average scores for the two Mechanics results when tested by an independent samples Mann-Whitney $U$ Test ( $p$ $=.004, d=0.38$ ) but no statistically significant difference was seen between the combined Waves and Special Relativity scores for the two years in question.

\section{Experiences and perspectives}

Students presented with the R-D-L method were asked during the final lecture to feedback on the method by using the TurningPoint audience response system. They were given the statement "The R-D-L has been ." and were presented with five

response options as shown in figure 2.

101 of 122 students (82.8\%) responded that the R-D-L method was either helpful or very helpful although this must be taken in the context that students were asked for their feedback at the end of their final Mechanics lecture, as opposed to during their revision period or after the end of semester examinations.

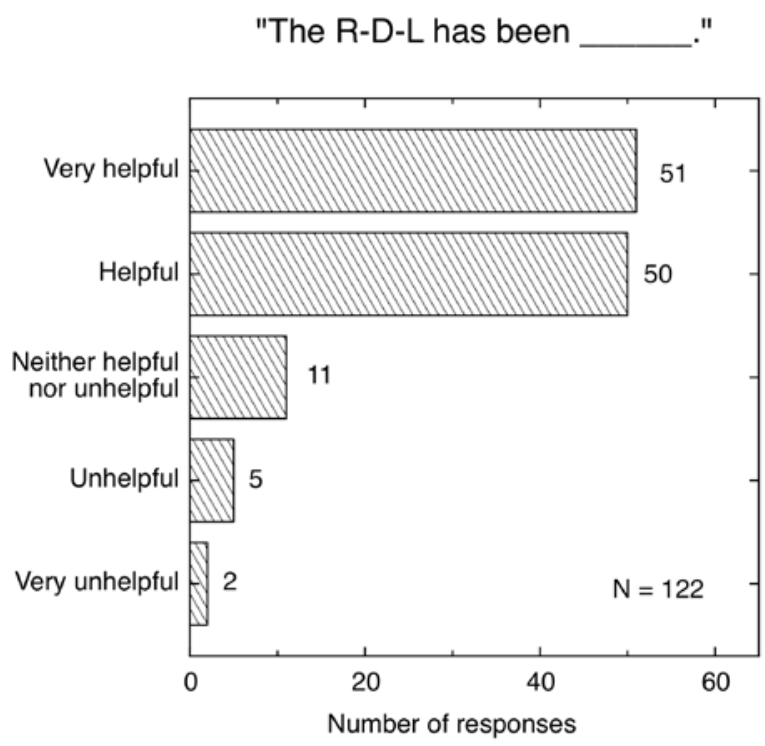

Figure 2: Anonymous student responses during final Mechanics lecture.

Whilst the gains of using the R-D-L method are small to moderate $(d=0.38)$ and may not compare with other innovations in teaching, what is particularly important from the author's perspective is the levels of input required to implement this method. The R-D-L method provides a very 'broad-stroke' level of signposting to the course textbook with the aim of encouraging students to identify their own areas of improvement, but this broad-stroke approach requires very little in the way of teacher preparation. Relevant chapters and sections (in particular any sections to omit if not covered in the syllabus) along with complete sets of questions were identified in the course textbook, as can be seen in figure 1 . In this example students were signposted to all of the questions associated with the lecture topic (in this case 35 questions in total) but were told to find questions that they feel would help them to better learn and understand the topic. It was emphasised that students were not required to do all questions.

Due to the coarse nature of finding the relevant textbook pages for the R-D-L components the implementation into the course material was no more than half an hours work on the part of the author. The emphasis on work was on the students to identify and address their own 
learning needs with the R-D-L information provided to guide them to the right general section of the course textbook. When the effect size and implementation time of the R-D-L method are considered together the benefit of this approach becomes much more clear: it can be an "easy win" for improvements (measured by examination scores) that can be implemented quickly, easily and without any prior experience or technical skills.

\section{Acknowledgements}

The author would like to acknowledge Drew Tarmey for helpful discussions during analysis of data, and to Paul Duckmanton and Nik Reeves-McLaren for useful comments on drafts of the manuscript.

\section{References}

Berger, P.L. and Luckmann, T. (1967) The Social Construction of Reality. New York: Doubleday.

Christensen, C.R. (1991) 'Premises and Practice of Discussion Teaching', in C. R. Christensen, D. A. Garvin and A. Sweet (eds) Education for Judgement: The Artistry of Discussion Leadership. Boston, MA: The Harvard Business School Press.

Cole, N.S. (1990) Conceptions of Education Achievement. Educational Researcher 19, 2-7.

Dehler, G.E. and Welsh, M.A. (2014) Against Spoon-Feeding. For Learning. Reactions on Students' Claims to Knowledge. Journal of Management Education 38, 875-893.

Duderstadt, J.J. (2000) A University for the 21st Century. The University of Michigan Press.

Gibbs, P. (2010) Higher Education as a Market: A problem or solution? Studies in Higher Education 26, 85-94.

Hinings, C.R. and Greenwood, R. (1988) The Dynamics of Strategic Change. Oxford: Basil Blackwell.
Jaffe, D. (1998) Institutionalized Resistance to Asynchronous Learning Networks. Journal of Asynchronous Learning Networks 2, 21-32.

Kensington-Miller, B., Novak, J. and Evans, T. (2016) Just do it: flipped lecture, determinants and debate. International Journal of Mathematical Education in Science and Technology 47, 853-862.

Lancaster, S.J. (2013) The Flipped Lecture. NDIR 9, 28-32.

Meyer, J.W. and Rowan, D. (1977) Institutional Organizations: Formal Structure as Myth and Ceremony. American Journal of Sociology 83, 340-363.

Newman, J.H. (1996). The Idea of a University. Yale University Press.

Overton, T.L. and Randles, C.A. (2015) Beyond problem-based learning: using dynamic PBL in chemistry. Chemistry Education Research and Practice 16, 251-259.

Raelin, J.A. (2008) Work-Based Learning: Bridging Knowledge and Action in the Workplace. San Francisco, CA: Jossey-Bass.

Raelin, J.A. (2009) The Practice Turn-Away: Forty Years of Spoon-Feeding in Management Education. Management Learning 40, 401410.

Seery, M.K. and McDonnell, C. (2013) The application of technology to enhance chemistry education. Chemistry Education Research and Practice 14, 227-228.

Smith, H. (2008) Spoon-feeding: or how i learned to stop worrying and love the mess. Teaching in Higher Education 13, 715-718.

Trow, M. (1974) "Problems in the transition from elite to mass higher education" from OECD, Policies for higher education. Paris: Organisation for Economic Co-operation and Development (OECD).

Young, H.D. and Freedman, R.A. (2012) University Physics with Modern Physics. San Francisco, CA: Addison-Wesley, 13th edition. 